\title{
Estabelecimento de cultura in vitro de Hibiscus sabdariffa L.: obtenção de plântulas e indução de calos em diferentes condições de cultura visando o acúmulo de biomassa
}

\author{
In vitro culture establishment of Hibiscus sabdariffa L.: obtaining seedlings and induction of callus \\ under different culture conditions aiming at biomass accumulation
}

Establecimiento de cultura in vitro de Hibiscus sabdariffa L.: obtención de plántulas e inducción de callos en diferentes condiciones de cultivo con el objetivo de la acumulación de biomasa

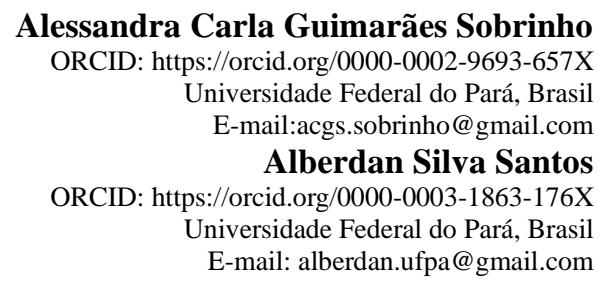

\begin{abstract}
Resumo
Hibiscus sabdariffa L., é uma planta pertencente à família Malvaceae Juss., conhecida popularmente como vinagreira, a espécie apresenta importância farmacológica. A cultura in vitro de calos representa um importante recurso para a produção contínua de compostos medicinais de alta qualidade, sendo possível a produção de biomassa com estes. O presente trabalho teve como objetivo verificar quais as condições necessárias de cultivo para a maior produção de massa calogênica úmida dos explantes (hipocótilos e raízes). Os explantes foram inoculados em diferentes meios básicos de cultura (MS e B5) suplementados com diferentes concentrações de reguladores de crescimento e mantidos em incubadora tipo B.O.D a $30^{\circ} \mathrm{C}$, fotoperíodo de $16 \mathrm{~h}$ de luz. A produção de calos foi avaliada através de aferição do peso úmido dos calos, após 120 dias de cultivo. Com base nos resultados obtidos no estudo, pode-se observar que a proliferação de calos de $H$. sabdariffa, ocorreu independente dos tipos de explantes, meios basais ou concentrações de reguladores de crescimento, 2,4-D e BAP, porém os melhores resultados para as produções de massas calogênicas dos hipocótilos e raízes foram em meio MS suplementado com $0,1 \mathrm{mg} . \mathrm{L}^{-1}$ de 2,4-D em combinação com $0,1 \mathrm{mg} . \mathrm{L}^{-1} \mathrm{de}$ BAP (T2), apresentando médias de massas calogênicas provenientes de explantes de hipocótilos $(7,43 \pm 0,19 \mathrm{~g})$ e de raízes $(6,75 \pm 0,07 \mathrm{~g})$. Os resultados mostram que as técnicas in vitro, apresentam vantagens de produção de biomassa em condições ambientais estéreis e controladas, permitindo um melhor controle dos processos de desenvolvimento e produção de tecidos ricos em compostos bioativos.
\end{abstract}

Palavras-chave: Biotecnologia; Calogênese; Meios de cultura; Reguladores de crescimento.

\begin{abstract}
Hibiscus sabdariffa L., is a plant that belong to the family Malvaceae Juss., popularly known as vinagreira, the species has pharmacological importance. The in vitro culture of callus represents an important resource for the continuous production of high quality medicinal compounds, being possible the production of biomass with compounds of medicinal interest. The present work aimed to verify the necessary cultivation conditions for the highest production of wet callogenic mass of explants (hypocotyls and roots). The explants were inoculated in different basic culture media (MS and B5) supplemented with different concentrations of growth regulators and kept in a B.O.D incubator at $30^{\circ} \mathrm{C}$, photoperiod of $16 \mathrm{~h}$ of light. Callus production was evaluated by measuring the wet weight of callus after 120 days of cultivation. Based on the results obtained in the study, it can be observed that the proliferation of $H$. sabdariffa, callus occurred regardless of the type of explants, basal media or concentrations of growth regulators, 2,4-D and BAP, but the best results for the production of callogenic masses of hypocotyls and roots were in MS medium supplemented with $0,1 \mathrm{mg} . \mathrm{L}^{-1}$ of 2,4-D in combination with $0,1 \mathrm{mg} . \mathrm{L}^{-1}$ of BAP (T2), presenting averages of callogenic masses from hypocotyl explants $(7,43 \pm 0.19 \mathrm{~g})$ and roots $(6,75 \pm 0.07 \mathrm{~g})$. The results show that in vitro techniques have advantages of biomass production in sterile and controlled environmental conditions, allowing a better control of the development processes and production of tissues rich in bioactive compounds.
\end{abstract}

Keywords: Biotecnology; Callogenesis; Culture media; Growth regulators. 


\begin{abstract}
Resumen
Hibiscus sabdariffa L., és una planta que perteneciente a la familia Malvaceae Juss., popularmente conocida como vinagreira, la especie tiene importancia farmacológica. El cultivo in vitro de callos representa un recurso importante para la producción continua de compuestos medicinales de alta calidad, siendo posible la producción de biomasa con compuestos de interés medicinal. El presente trabajo tenía como objetivo verificar las condiciones de cultivo necesarias para la mayor producción de masa callogénica húmeda de explantes (hipocotilos y raíces). Los explantes fueron inoculados en diferentes medios de cultivo básico (MS y B5) complementados con diferentes concentraciones de reguladores de crecimiento y mantenidos en una incubadora B.O.D a $30^{\circ} \mathrm{C}$, fotoperiodo de $16 \mathrm{~h}$ de luz. La producción de callos se evaluó midiendo el peso húmedo de los callos después de 120 días de cultivo. Sobre la base de los resultados obtenidos en el estudio, se puede observar que la proliferación de callos de $H$. sabdariffa, ocurrió independientemente de los tipos de explantes, medios basales o concentraciones de reguladores de crecimiento, 2,4-D y BAP, pero los mejores resultados para la producción de masas callogénicas de hipocotilos y raíces fueron en MS medio complementado con $0,1 \mathrm{mg} . \mathrm{L}^{-1}$ de 2,4-D en combinación con $0,1 \mathrm{mg} . \mathrm{L}^{-1}$ de BAP (T2), presentando promedios de masas callogénicas de explantes de hipocotilo $(7,43 \pm 0,19 \mathrm{~g})$ y raíces $(6,75 \pm 0,07 \mathrm{~g})$. Los resultados muestran que las técnicas in vitro tienen ventajas de la producción de biomasa en condiciones ambientales estériles y controladas, permitiendo un mejor control de los procesos de desarrollo y producción de tejidos ricos en compuestos bioactivos.
\end{abstract}

Palabras clave: Biotecnología; Callogénesis; Medios de cultura; Reguladores de crecimiento.

\title{
1. Introdução
}

O Brasil apresenta uma das maiores biodiversidades em espécies de plantas do mundo, e essa biodiversidade é considerada uma fonte inigualável de substâncias biotivas e de grande diversidade funcional e estrutural, portanto, de grande utilidade para a busca de novos fármacos e outros bioprodutos (Jamshidi-Kia et al., 2018). Assim, o conhecimento sobre os aspectos da biodiversidade brasileira vem evoluindo a passos largos. Especialmente através da utilização de produtos naturais, derivados da flora, sendo uma alternativa para a prevenção, tratamento e/ou cura de diversas enfermidades (Firmo et al., 2011). Entre os elementos que constituem para essa biodiversidade, estão às plantas medicinais que são importantes fontes de compostos bioativos provenientes do metabolismo secundário vegetal (Fumagali et al., 2008; Barreiro \& Bolzani, 2009, De Souza Eller et al., 2015; Lorenzi \& Matos, 2021).

Estudar essas substâncias provenientes do metabolismo secundário dos vegetais (fitoconstituintes), destinados à sua defesa e proteção, é de fundamental importância científica, pois apenas 5\% destas plantas têm sido estudadas fitoquimicamente e uma porcentagem ainda menor são avaliadas sob os aspectos biológicos (Fumagali et al., 2008; Barreiro \& Bolzani, 2009). Entre essas atividades biológicas pode-se citar a fotoprotetora, antioxidante (Tambor et al., 2016) e antimicrobiana (De Sá Junior et al., 2016), além disso os fitoconstituintes identificados a partir de plantas medicinais representam uma excelente oportunidade para o desenvolvimento científico (Birari \& Bhutani, 2007).

Os recursos vegetais apresentam um valor essencial na biodiversidade, pois nela existem variabilidades de espécies vegetais que em sua maioria proporcionam benefícios ao homem, tanto através da alimentação quanto para finalidades farmacêuticas (Kinupp \& Lorenzi, 2015; Lorenzi \& Matos, 2021). Nesse cenário, o H. sabdariffa, que é nomeada no Brasil de vinagreira, pertencente à família das Malvaceae, sendo empregada tradicionalmente para finalidades médicas, devido a presença de compostos com propriedades medicinais em seus extratos, apresentando inúmeras qualidades farmacológicas evidenciadas cientificamente, como antioxidante, anti-inflamatório, antidiabético, entre outros (Borrás-Linares et al., 2015; Kapepula et al., 2017; Naveed et al., 2018; Sobrinho et al. 2020a).

Devido à grande busca da população por produtos naturais, as plantas medicinais estão em crescente demanda, logo, faz-se necessário à utilização de processos de cultivo de espécies com potenciais farmacológicos como a $H$. sabdariffa, através de processos biotecnológicos como a cultura de tecidos vegetais. Nos últimos anos, a industrial tem apresentado interesse em pesquisas baseadas na cultura de tecidos vegetais in vitro, de forma a estabelecer condições ideais de crescimento e multiplicação de plantas medicinais (Shekhawat \& Manokari, 2016; França, 2017). No entanto, a propagação in vitro ou micropropagação ainda precisa de maiores desenvolvimentos de protocolos para as espécies que apresentem capacidade 
medicinal (Oliveira et al., 2013). Portanto, a cultura de tecidos vegetais in vitro oportuniza uma ferramenta biotecnológica de grande importância para a produção sustentável dessas fontes vegetais, garantindo a produção regular e em larga escala em menor tempo, além disso, auxilia na produção de biomassa que apresente compostos de capacidade farmacológica através da calogênese (Andrade, 2002).

O calo é uma massa indiferenciada de células parenquimatosas, dependente do uso dos meios básicos incluindo macro e microelementos para o crescimento das plantas e uma combinação de reguladores de crescimento para promover divisão celular e crescimento em condições estéreis e ambiente controlado (Mansuroglu \& Gurel, 2001; Shirin et al., 2007; Hoesen \& Sukamto, 2008; Jahan et al., 2009), além de componentes orgânicos, carboidratos, explantes e materiais adjuvantes (Pawar et al. 2015).

Os meios de cultura como o MS desenvolvido por Murashige \& Skoog (1962), e o B5 estabelecido por Gamborg et al., (1968) são um dos mais utilizados na cultura in vitro, apresentando como componente-chave o nitrogênio, elemento associado ao controle do crescimento, diferenciação e morfogênese (Lakshmanan \& Taji, 2000).

Em relação aos reguladores de crescimento, de acordo com Nakasha et al., (2016), uma auxina como o ácido 2,4diclorofenoxiacético (2,4-D) é ideal para a indução de calos, sendo o hormônio mais usado para iniciar a calogênese em várias plantas. Entre as citocininas, a 6-benzilaminopurina (BAP) interage ativamente quando adicionada ao meio basal juntamente com o 2,4-D para o início do calo e sua manutenção. Por esse motivo, existe a necessidade de definir o tipo e a concentração de reguladores de crescimento no meio de cultura, sendo estes fatores importantes no desenvolvimento in vitro de espécies vegetais (Hartmann et al., 2004).

Nesse sentido, a presente investigação foi realizada com o objetivo de desenvolver um protocolo in vitro eficiente para obtenção de plântula e indução de calos de H. sabdariffa, empregando diferentes meios de cultura e variações de concentrações de reguladores de crescimento, uma vez que são poucos os trabalhos com protocolos de propagação in vitro para a espécie que objetive o acúmulo de biomassa. Na Figura 1, observa-se o resumo gráfico do desenvolvimento da pesquisa.

Figura 1: Resumo gráfico, as sementes da $H$. sabdariffa que estavam presentes nas cápsulas maduras da espécie sofreram a desinfestação para a germinação in vitro, sendo obtidas plântulas axênicas, seus explantes (hipocótilos e raízes) foram utilizados para a indução de calos em diferentes condições de cultura com a finalidade de acúmulo de biomassa.

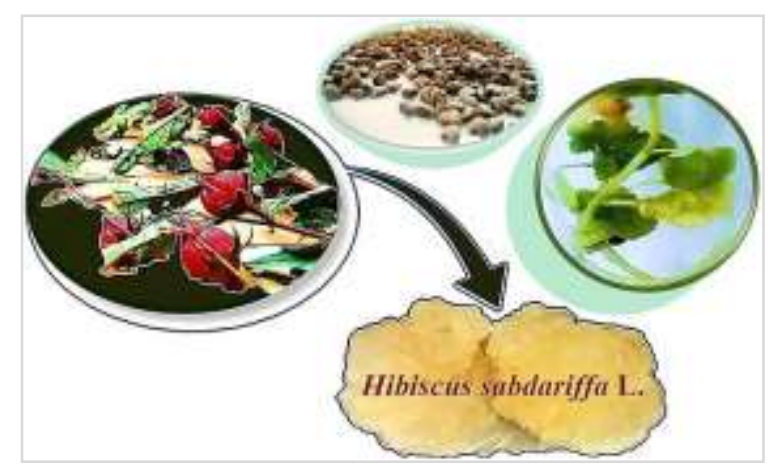

Fonte: Autores.

\section{Metodologia}

\subsection{Material vegetal}

Foram utilizadas sementes da espécie $H$. sabdariffa, obtidas a partir de cápsulas maduras como fonte primária de explante, coletadas na Vila de Pau D’Arco município de Santa Bárbara do Pará, estando a matriz localizada na área com as seguintes coordenadas geográficas S: $1^{\circ} 15^{\prime} 3,88^{\prime \prime}$; O: $48^{\circ} 16^{\prime} 36,8$, com registro de atividades de acesso ao Patrimônio 
Genético e do Conhecimento Tradicional Associado (SisGen) sob número AF05B99. Após a colheita, as sementes foram transportadas até o Laboratório de Investigação Sistemática em Biotecnologia e Biodiversidade Molecular (LabISisBio.), localizado na Rua Augusto Correa, 01, Guamá, 66075-110 Belém, PA, da Universidade Federal do Pará. Antes de serem inoculadas no meio de cultivo essas sementes foram submetidas a um processo de desinfestação.

\subsection{Desinfestação das sementes de $\boldsymbol{H}$. sabdariffa, germinação in vitro e obtenção de plântulas.}

As contaminações na cultura de $H$. sabdariffa ocorrem quando as condições de cultivo não são ideais, as características morfológicas da planta influenciam negativamente o sucesso da cultura, pois as espécies do gênero hibiscus são plantas lenhosas, sendo seu explante inicial a principal fonte de contaminantes apresentando características anatômicas que permitem o acúmulo de agentes contaminantes dificultando a assepsia (Cruz et al., 2003). Sendo assim, os contaminantes são uma preocupação na cultura in vitro do $H$. sabdariffa, pois afeta diretamente o crescimento de plântulas in vitro, assim o máximo cuidado em cada etapa do cultivo pode levar ao sucesso da cultura (Sobrinho et al. 2020b).

Nesse sentido, para o estabelecimento das condições de germinação in vitro foi necessário realizar um tratamento adequado de desinfestação das sementes, o que permitiu continuar com o desenvolvimento das diferentes etapas da cultura. Primeiramente, as sementes foram classificadas de acordo com seu grau de maturação e foi feito uma pré-assepsia fora da câmara de fluxo, que consistiu em lavagens das sementes com água estéreo e Tween 80, em seguida ouve a imersão em etanol a $70 \%$ por um minuto, e adição de $\mathrm{NaClO}$ a 2,5\% (v/v) por 15 minutos, lavagem com $\mathrm{H}_{2} \mathrm{O}$ destilada estéreo e posterior imersão em fungicida Derosal 0,5\% (v/v) por 60 minutos. Após esse período, as sementes foram retiradas do fungicida e imersas em solução de nitrato de oxiconazol + cloranfenicol $25 \mathrm{mg}$. $\mathrm{L}^{-1}$ e mantidas em incubadora com agitação orbitalar por 48 horas.

Em seguida as sementes foram submetidas à assepsia dentro da câmara de fluxo laminar, que consistiu em imersão das sementes em solução de etanol a 70\% (v/v) por 4 minutos e solução de hipoclorito de sódio a 2,5\% (v/v) por 20 minutos, seguida de lavagens com água destilada estéreo. Após a esterilização em câmara de fluxo laminar, as sementes foram inoculadas em frascos cilíndricos de vidro com dimensões de $5 \mathrm{~cm} \times 10 \mathrm{~cm}$ contendo $40 \mathrm{ml}$ de meio de cultura MS, suplementado com 30 g.L. $\mathrm{L}^{-1}$ de sacarose, solidificado com Phytagel 0,2 \%, sob temperatura $30^{\circ} \mathrm{C}$. O pH do meio foi ajustado para 5,8, o sistema foi autoclavado a $121^{\circ} \mathrm{C}$ durante 20 minutos. Em seguida os frascos inoculados foram mantidos em incubadora tipo B.O.D a $30^{\circ} \mathrm{C}$, fotoperíodo de $16 \mathrm{~h}$ de luz e intensidade luminosa de $90 \mu \mathrm{mol} . \mathrm{m}^{-2} . \mathrm{s}^{-1}$ por 120 dias para obtenção da plântula axênica.

O meio basal MS foi escolhido para a germinação e obtenção de plântula, pois apesar de sua alta concentração de sal, é aquele que permite o melhor crescimento em várias espécies (Alvarenga et al., 2015; Grzegorczyk-Karolak et al. 2015; Rahman et al., 2015).

\subsection{Indução de calos de $\boldsymbol{H}$. sabdariffa em diferentes condições de cultura.}

A sacarose é a fonte de carbono mais frequentemente usada nos meios basais de células vegetais, sendo de grande importância o conhecimento da concentração desse componente para o melhor desenvolvimento de calos e regeneração dos tecidos (Gamborg \& Murashige, 1976; Verma et al., 2016). Tem-se na composição dos meios de cultura o mio-inositol que apesar de não essencial é frequentemente acrescentado aos meios de cultura, pois melhora o crescimento de calos (Gamborg \& Murashige, 1976).

Para o processo de indução de calos foram utilizados os meios de cultura com as formulações minerais e vitamínicas dos meios básicos MS e B5 (Tabela 1). 
Tabela 1: Composição nutricional dos meios básicos Murashige \& Skoog (1962), e Gamborg, et al. (1968) em mg.L-1

\begin{tabular}{|c|c|c|c|c|c|}
\hline $\begin{array}{l}\text { Composição dos meios } \\
\text { de cultura }\left(\mathrm{mg} \cdot \mathrm{L}^{-1}\right)\end{array}$ & MS & B5 & $\begin{array}{l}\text { Composição dos meios } \\
\text { de cultura }\left(\mathrm{mg} . \mathrm{L}^{-1}\right)\end{array}$ & MS & B5 \\
\hline Macronutrientes & - & - & Micronutrientes & - & - \\
\hline $\mathrm{NH}_{4} \mathrm{NO}_{3}$ & 1.650 & - & $\mathrm{MnSO}_{4} \cdot \mathrm{H}_{2} \mathrm{O}$ & 22.3 & 10 \\
\hline $\mathrm{KH}_{2} \mathrm{PO}_{4}$ & 170 & - & $\mathrm{ZnSO}_{4} \cdot 7 \mathrm{H}_{2} \mathrm{O}$ & 8.6 & 2 \\
\hline$\left(\mathrm{NH}_{4}\right)_{2} \mathrm{SO}_{4}$ & - & 134 & $\mathrm{H}_{3} \mathrm{BO}_{3}$ & 6.2 & 3 \\
\hline $\mathrm{KNO}_{3}$ & 1.900 & 2.500 & $\mathrm{KI}$ & 0.83 & 0.75 \\
\hline $\mathrm{MgSO}_{4} .7 \mathrm{H}_{2} \mathrm{O}$ & 370 & 250 & $\mathrm{Na}_{2} \mathrm{MoO}_{4} \cdot 2 \mathrm{H}_{2} \mathrm{O}$ & 0.25 & 0.25 \\
\hline $\mathrm{CaCl}_{2} \cdot 2 \mathrm{H}_{2} \mathrm{O}$ & 440 & - & $\mathrm{CuSO}_{4} .5 \mathrm{H}_{2} \mathrm{O}$ & 0.025 & 0.025 \\
\hline $\mathrm{NaH}_{2} \mathrm{PO}_{4} \cdot \mathrm{H}_{2} \mathrm{O}$ & - & 150 & $\mathrm{CoCl} .6 \mathrm{H}_{2} \mathrm{O}$ & 0.025 & 0.025 \\
\hline Fe- EDTA & - & - & Vitaminas & - & - \\
\hline $\mathrm{FeSO}_{4} .7 \mathrm{H}_{2} \mathrm{O}$ & 27.8 & 27.8 & Tiamina $-\mathrm{HCl}(\mathrm{B} 1)$ & 0.1 & 10 \\
\hline $\mathrm{Na}_{2}$ EDTA & 37.3 & 37.3 & Piridoxina - $\mathrm{HCl}$ & 0.5 & 1 \\
\hline Cálcio & - & - & Ácido Nicotínico & 0.5 & 1 \\
\hline $\mathrm{CaCl}_{2} \cdot 2 \mathrm{H}_{2} \mathrm{O}$ & - & 150 & Glicina & 2 & - \\
\hline Fonte de carbono & - & - & Mio- Inositol & 100 & 100 \\
\hline Sacarose & 30.000 & 20.000 & pH & 5.8 & 5.8 \\
\hline
\end{tabular}

Fonte: Autores.

Os meios de cultura foram suplementados com $30 \mathrm{~g} . \mathrm{L}^{-1}$ de sacarose, solidificado com Phytagel 0,2 \% para o MS e 20 g. $\mathrm{L}^{-1}$ de sacarose, solidificado com ágar $0,7 \%$ para o B5, em duas diferentes concentrações $\left(\mathrm{T}_{1}\right.$ e $\left.\mathrm{T}_{2}\right)$ de reguladores de crescimento, 2,4-D (ácido 2,4-diclorofenoxiacético) e BAP (6-benzilaminopurina), provenientes da matriz experimental, (Tabela 2), sob temperatura $30{ }^{\circ} \mathrm{C}$ e com o $\mathrm{pH}$ do meio ajustado para 5,8 , o sistema foi autoclavado a $121^{\circ} \mathrm{C}$ durante 20 minutos.

Tabela 2: Meios basais MS e B5 em diferentes concentrações de reguladores de crescimento, 2,4-D e BAP, utilizados para indução de calos a partir de explantes hipocotiledonar e radiculares de H. sabdariffa.

\begin{tabular}{ccccc}
\hline Meios de Cultura & Tratamentos & $\mathbf{2 , 4 - D}\left(\mathbf{m g . L ^ { - 1 }}\right)$ & BAP $\left(\mathbf{m g . L ^ { - 1 }}\right)$ & Explantes \\
\hline \multirow{2}{*}{ MS } & $\mathrm{T}_{1}$ & 1,0 & 0,2 & Hipocótilos / Raízes \\
& $\mathrm{T}_{2}$ & 0,1 & 0,1 & \\
\multirow{2}{*}{ B5 } & $\mathrm{T}_{1}$ & 1,0 & 0,2 & Hipocótilos / Raízes \\
& $\mathrm{T}_{2}$ & 0,1 & 0,1 & \\
\hline
\end{tabular}

Fonte: Autores.

Foram utilizados explantes de hipocótilos e raízes de $H$. sabdariffa, oriundos do cultivo axênico. Os explantes foram fragmentados $(1 \mathrm{~cm})$ e seus segmentos inoculados, sendo utilizado quatro seguimentos de cada explante em um único frasco de cultura $(5 \mathrm{~cm}$ x $10 \mathrm{~cm})$, contendo $40 \mathrm{ml}$ dos respectivos meios de cultura, em um total de duas repetições para cada tratamento. Os frascos contendo os meios basais em seus respectivos tratamentos e explantes foram previamente pesados utilizando-se balança analítica e posteriormente distribuídos em incubadora tipo B.O.D a $30^{\circ} \mathrm{C}$ com fotoperíodo de $16 \mathrm{~h}$ de luz e intensidade luminosa de $90 \mu \mathrm{mol} \cdot \mathrm{m}^{-2} \cdot \mathrm{s}^{-1}$, mantidos por 120 dias.

O processo de indução de calo foi avaliado ao término dos 120 dias. Os frascos de cultura contendo os calos foram retirados da incubadora tipo B.O.D com o propósito de aferição da massa calogênica úmida, após a pesagem, os calos foram retirados dos frascos de cultura em câmara de fluxo e colocados em placas de petri estéreis, para o estudo das qualidades morfológicas, observando a consistência, compacto ou friável, que de acordo com Evans et al. (2003) o calo compacto é densamente compactado com textura dura, já os calos friáveis consistem em células sobrepostas que facilmente de desagregam, também foram observadas as colorações de cada calo (branco, verde, amarelo e marrom) para registro, sendo 
posteriormente transferidos para os meios basais com as concentrações de reguladores de crescimento de origem, para estudos posteriores.

\section{Resultados e Discussão}

\subsection{Germinação in vitro e obtenção de plântulas.}

A germinação de sementes in vitro de $H$. sabdariffa foi alcançada em meio MS desprovido de reguladores de crescimento e possibilitou a obtenção da plântula in vitro (Figura 2).

Figura 2: Germinação, desenvolvimento e estabelecimento de plântula in vitro de H. sabdariffa em meio de cultura MS.
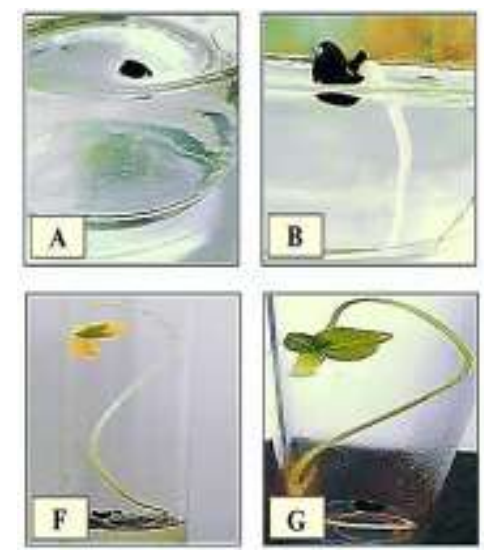
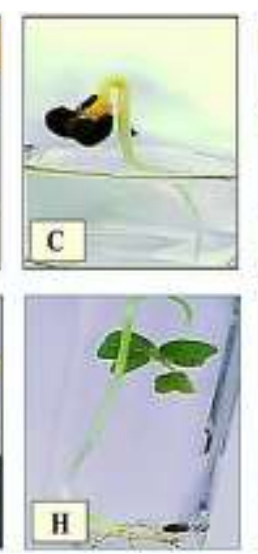

Fonte: Autores.
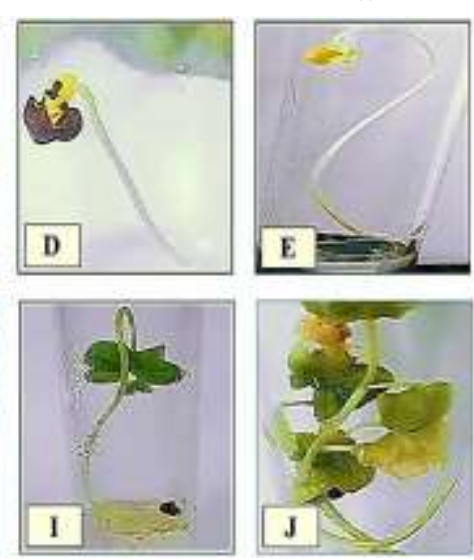

A natureza a germinação das sementes de H. sabdariffa é dificultada por diversos fatores (Brasil, 2009). O tegumento é duro e maciço, podendo apresentar dormência (Eichelberger \& Moraes, 2001), porém o protocolo para a germinação in vitro e obtenção da plântula possibilitou uma maior absorção de meio de cultura, permitindo a germinação in vitro. Na Figura 2 , observa-se a semente absorvendo o meio nutritivo (A). A protrusão da radícula e alongamento da radícula (B e C). A germinação é do tipo epígeo (Brasil, 2009), com a elevação dos cotilédones acima da superfície do meio nutritivo, fanerocotiledonar, com o tegumento aderido aos cotilédones (D). Os cotilédones totalmente livres do tegumento (E). Os cotilédones totalmente desdobrados $(\mathrm{F})$. A primeira folha verdadeira desdobrada $(\mathrm{G})$. Segunda folha verdadeira desdobrada (H). Terceira folha verdadeira desdobrada (I). E o desenvolvimento da parte aérea da plântula axênica ao final dos 120 dias (J).

Houve um retardo no desenvolvimento das partes aéreas da plântula in vitro ocasionando uma redução no tamanho das mesmas, que segundo Kanashiro et al. (2007), é devido a concentração elevada de $\mathrm{NH}_{4}{ }^{+}$e $\mathrm{NO}_{3}{ }^{-}$no meio basal MS. No estudo realizado por Sobrinho et al. (2020b) para a $H$. sabdariffa, germinado em ambiente natural, os cotilédones apresentaram-se desenvolvidos, mas as raízes mostraram-se pouco desenvolvimento em tamanho e espessura. De acordo com Mercier e Kerbauy (1998) os íons de nitrato e amônio presentes no meio de cultura promovem o aumento dos níveis de auxina no interior da planta, favorecimento o desenvolvimento das raízes, o que pode ser observado para o cultivo in vitro de $H$. sabdariffa, a raiz principal apresentou desenvolvimento em tamanho e espessura, sendo observada a presença de raízes laterais como mostra a Figura 3. 
Figura 3: Raízes desenvolvidas da plântula in vitro de $H$. sabdariffa cultivadas em meio MS.

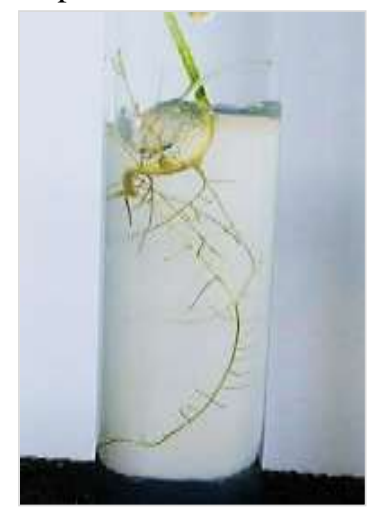

Fonte: Autores.

\subsection{Indução de calos em diferentes condições de cultura.}

\subsubsection{Qualidades morfológicas dos calos de $\boldsymbol{H}$. sabdariffa}

$\mathrm{Na}$ cultura in vitro de tecidos vegetais, os fitohormônios, auxina e citocinina, influenciam o desenvolvimento das células, podendo induzir e nutrir uma massa celular pluripotente desorganizada, conhecida como calo, a partir dos explantes (Ikeuchi \& Sugimoto, 2013). Assim, no processo de indução de calos, os explantes como os hipocótilos e raízes excisadas que foram cultivados em diferentes meios de cultura (MS e B5) e em distintas concentrações de reguladores de crescimento, ( $T_{1}$ e $\mathrm{T}_{2}$ ), apresentaram qualidades morfológicas diferenciadas para cada tipo de explante nas diferentes condições de cultura (Figura $4)$.

Figura 4: Indução de calos de $H$. sabdariffa. de origem hipocotiledonar (A, B, E, F) e radicular (C, D, G, H) inoculados em diferentes meios básicos de cultura (MS- Linha acima / B5- Linha abaixo) e suplementados com diferentes concentrações de reguladores de crescimento $\left(\mathrm{T}_{1}-\mathrm{A}, \mathrm{C}, \mathrm{E}, \mathrm{G} / \mathrm{T}_{2}-\mathrm{B}, \mathrm{D}, \mathrm{F}, \mathrm{H}\right)$. Barras $=1 \mathrm{~cm}$.
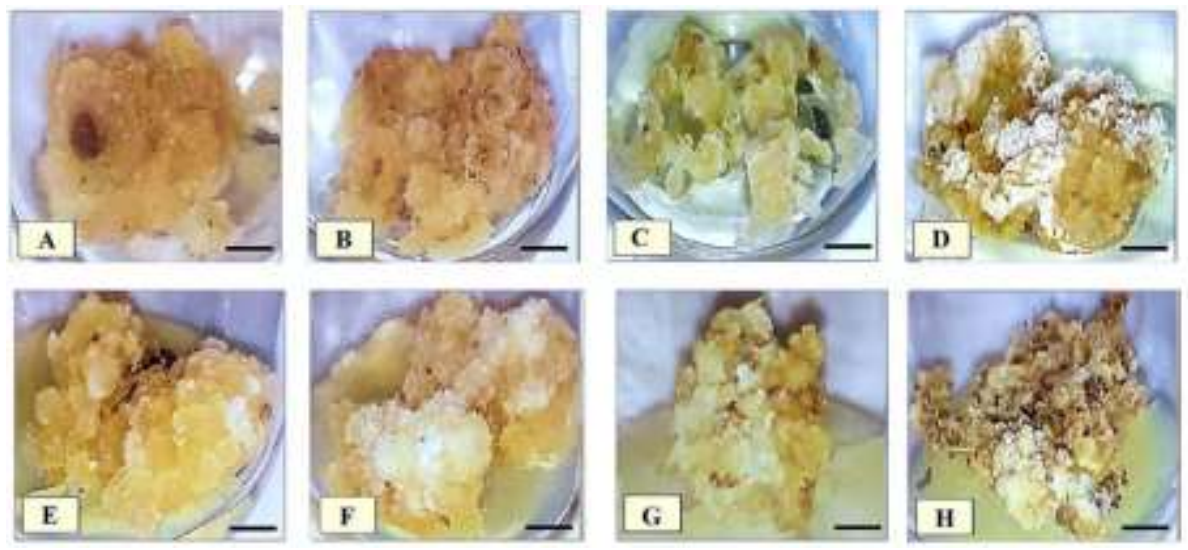

Fonte: Autores.

As alterações de fatores externos, como tipos de meios basais e reguladores de crescimento de plantas, podem influenciar as potencialidades indução e a morfologia do calo. (Staba, 1980). No entanto, nenhuma generalização definitiva pode ser feita em relação a esses fatores, uma vez que as disposições morfogênicas dos calos podem variar de acordo com a espécie (Avilés et al., 2009).

Assim sendo, os resultados do estudo demonstraram que houve a indução de calos independente dos tipos de explantes e condições de cultura. Registrou-se a formação de calos com características friáveis para explantes de hipocótilos em meio de cultura MS, no tratamento $\mathrm{T}_{1}$ e $\mathrm{T}_{2}$ (A e B), apresentando células de fácil desagregação, com textura macia, devido 
o afrouxamento da parede celular (Bekheet et al., 2014; Ashrafzadeh et al., 2015), também foi possível observar a formação de grupos de aglomerados compactos de células justapostas, denominadas de calos compactos, de coloração amarela com regiões esbranquiçadas para os explantes de hipocótilo em meio B5 no tratamento $\mathrm{T}_{1}$ e $\mathrm{T}_{2}$ (E, F). Tais características, segundo Shukla et al., (2014), são devido ao impacto inibitório do 2,4-D na formação da clorofila podendo causar calos esbranquiçados ou amarelados. Os calos hipocotiledonares em meio MS e B5 em T 1 (A e E) apresentaram oxidações na região de excisão dos explantes, conferindo a estes calos uma região de coloração marrom.

Os calos radiculares apresentaram características friáveis, crescendo separadamente em partes menores, com facilidade de corte devido à alta presença de água e apresentando coloração amarela. Segundo Nasution \& Nasution, (2019), as cores verde, branco, amarelo mostram que as células ainda se dividiam ativamente, enquanto cores como marrom e preto são sintomas de envelhecimento das células, o que inibirá o crescimento do calo, característica essa que foi observada no calo radicular em meio $\mathrm{B} 5$ em $\mathrm{T}_{2}(\mathrm{H})$ apresentando oxidação que se propagou, conferindo a este calo uma coloração marrom em grande parte de sua extensão. O que pode ser um indicativo de produção de compostos fenólicos que podem ser tóxicos, interrompendo o crescimento do calo (Hayati et al., 2014).

\subsubsection{Condições de cultura de calos de $\boldsymbol{H}$. sabdariffa para o acúmulo de biomassa}

As regulações nutritivas dos meios basais auxiliam expressivamente o desenvolvimento de calos. Os meios de cultura são os requisitos nutricionais básicos das células vegetais cultivadas e são muito semelhantes aos das plantas inteiras. O meio de Murashige e Skoog (MS) e o meio de Gamborg, Miller \& Ojima (B5) são todos altamente concentrados em macronutrientes (Zouzou et al., 2000). A escolha de um meio de cultura apropriado para estabelecer culturas in vitro é essencial, além das diferentes concentrações de reguladores de crescimento, sendo importantes na quantidade de biomassa dos calos obtidos (Nagella \& Murthy, 2010).

No estudo, o meio basal MS foi o mais apropriado para a o acúmulo de biomassa que o meio basal B5, apresentando maior produção de massa calôgenica nas concentrações de reguladores de crescimento de $0,1 \mathrm{mg} . \mathrm{L}^{-1}$ de 2,4 D e $0,1 \mathrm{mg} \cdot \mathrm{L}^{-1} \mathrm{de}$ BAP $\left(T_{2}\right)$ proporcionando as maiores médias de massas calogênicas úmidas provenientes de explantes hipocotiledonares $(7,43$ $\pm 0,19 \mathrm{~g})$ e radiculares $(6,75 \pm 0,07 \mathrm{~g})$ (Figura 5 ).

Figura 5: Valores médios de massa calogênica úmida (g) em diferentes meios de cultura com concentrações variadas de reguladores de crescimento para explantes hipotitiledonares e radiculares de $H$. sabdariffa.

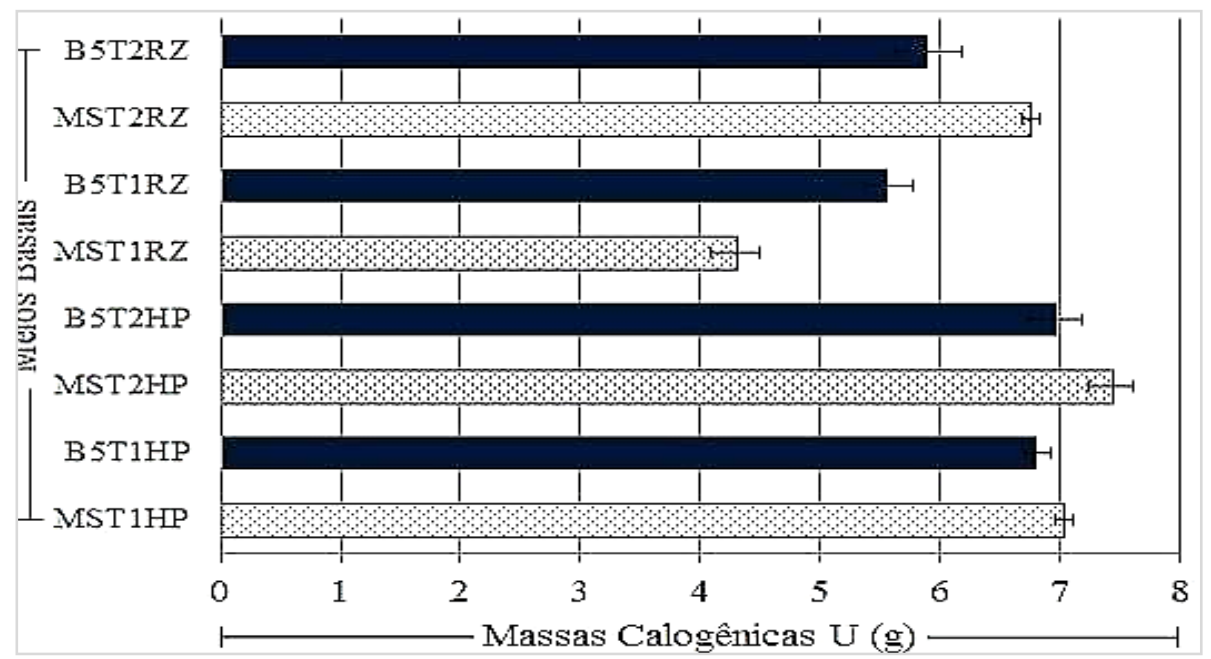

Fonte: Autores. 
Os explantes de tecidos hipocotiledonares jovens contribuíram para a maior produção de massa calogênica, sendo necessário para a promoção da cultura no acúmulo de biomassa calogênica, pois o tipo de explante e provavelmente sua estrutura anatômica desempenharam um papel significativo na iniciação do calo (Ishii et al., 2004). No estudo, a menor concentração de reguladores de crescimento favoreceu a proliferação de calos de $H$. sabdariffa, estimulando a produção de massa calogênica e de acordo com Ngomuo et al., (2014) os tipos de explantes usados para a cultura in vitro tem um grande efeito na indução de calos quando diferentes concentrações de reguladores de crescimento são utilizadas.

A melhor combinação de explante, meio basal e reguladores de crescimento para o acúmulo de biomassa, poderiam influenciar o acúmulo e a síntese de metabólitos secundários na cultura de células vegetais (Murthy et al., 2014). As massas calogênicas podem produzir altas quantidades de metabólitos secundários (Wani \& Snehal, 2010; Efferth, 2019), podendo padronizar a produção de compostos, sendo sugerido que a quantidade da produção de massa calogênica e a quantidade de produção de metabólitos secundários podem ser semelhantes por unidade de massa, sendo o cultivo in vitro uma das tecnologias empregada para melhorar a qualidade das plantas, aumentar a biomassa e a produtividade dessas espécies (Sitorus et al., 2011; Ariati et al., 2012).

Os metabólitos secundários são altamente diversificados e suas alterações dependem de interações químicas entre as plantas e seu ambiente (Kutchan, 2001), porém a abordagem da cultura in vitro de tecidos vegetais é independente das condições ambientais, logo, existe a possibilidade de produzir continuamente esses compostos bioativos (Karuppusamy, 2009; López-Laredo et al., 2009) possibilitando a manipulação das vias de biossíntese das células vegetais para produção de derivados de metabólitos secundários com características aperfeiçoadas (Hussain et al., 2012), ampliando a produção de metabólitos de interesse através de culturas de suspensão de células (Morales-Rubio et al., 2016 ).

\section{Conclusão}

A abordagem biotecnológica da cultura in vitro de vinagreira (H. sabdariffa), ajuda na conservação e multiplicação da espécie, sendo possível estimar os parâmetros significativos da investigação para a maior produção de biomassa calogênica em diferentes condições de cultura, e concentrações de reguladores de crescimento de plantas. O tratamento ideal para o estudo foi a combinação de meio MS na concentração de reguladores de crescimento de plantas de $0,1 \mathrm{mg} \mathrm{L}^{-1}$ de $2,4 \mathrm{D}$ e $0,1 \mathrm{mg} \mathrm{L}^{-1}$ de BAP. $\left(\mathrm{T}_{2}\right)$.

No futuro, esse protocolo facilitará a produção de biomassa calogênica de $H$. sabdariffa, sendo uma alternativa adequada para produção continuada dos compostos bioativos quando comparada aos métodos tradicionais em ambiente natural, evitando a superexploração da espécie, uma vez que a espécie produz variados compostos com capacidade farmacológica. A técnica in vitro pode superar a produtividade da planta em campo, através da possibilidade de modulação dessa resposta. No entanto, o processo tem muitos desafios, envolvendo os protocolos de cultivo in vitro, sendo necessária uma exploração dos períodos de subcultivos de calos nas combinações ideais para obtenção de uma maior biomassa e avaliando os estágios de desenvolvimento, assim como investigações que visem à utilização dessa cultura de calos como fonte de metabólitos secundários em um tempo relativamente curto, com qualidade e em níveis de conteúdo superior de componentes com bioatividade farmacológica.

\section{Agradecimentos}

O presente trabalho foi realizado com apoio da Coordenação de Aperfeiçoamento de Pessoal de Nível Superior Brasil (CAPES) - Código de Financiamento 001.

A Universidade Federal do Pará - UFPA e ao Programa de Pós-graduação da Rede de Biodiversidade e Biotecnologia da Amazônia Legal - BIONORTE, pela oportunidade de realização do curso de pós-graduação em nível de Doutorado. 


\section{Referências}

Alvarenga, I. C. A., Pacheco, F. V., Silva, S. T., Bertolucci, S. K. V. \& Pinto, J. E. B. P. (2015). In vitro culture of Achillea millefolium L.: quality and intensity of light on growth and production of volatiles. Plant Cell, Tissue and Organ Culture (PCTOC), 122, 299-308.

Andrade, S. R. M. (2002). Princípios da cultura de tecidos vegetais. (58a ed.), Embrapa cerrados, 16p.

Ariati, S. N., Waeniati, M. \& Suwastika, I. N. (2012). Induksi kalus tanaman kakao (Theobroma cacao L.) pada media MS dengan penambahan 2,4-D, BAP dan air kelapa. Natural Science: Journal of Science and Technology, 1(1), 74-84.

Ashrafadeh, S., Gaw, S., Glover, C. N. \& Leung, D. W. M. (2015). Differential cadmium resistance of two morphologically distinct types of potato (Solanum tuberosum) callus. Biologia (Bratislava), 70(5), 581-587.

Avilés, F., Rios, D., González, R. \& Sánchez-Olate, M. (2009). Effect of culture medium in callogenesis from adult walnut leaves (Juglans regia L.). Chilean Journal of Agricultural Research, 69(3), 460-467.

Barreiro, E. J. \& Bolzani, V. S. (2009). Biodiversidade: fonte potencial para a descoberta de fármacos. Química Nova, 32(3), 679-688.

Bekheet, S. A., El-Bahr, M. K., Sanaa, A., Ali, S. A. \& Hamed, M. A. (2014). Callus production of globe artichoke and milk thistle: in vitro hypolipidemic and antioxidant activities. World Journal of Pharmaceutical Research, 3, 1-17.

Birari, R. B. \& Bhutani, K. K. (2007). Pancreatic lipase inhibitorsfrom natural sources: unexplored potential. DrugDiscovery Today, $12(19 / 20), 879-89$.

Borrás-Linares, I., Fernández-Arroyo, S., Arráez-Roman, D., Palmeros-Suárez, P. A., Val-Díaz, R. D., Andrade-Gonzáles, I., Fernández-Gutiérrez, A., Gómez-Leyva, J. F. \& Segura-Carretero, A. (2015). Characterization of phenolic compounds, anthocyanidin, antioxidante and antimicrobial activity of 25 varieties of Mexican Roselle (Hibiscus sabdariffa). Industrial Crops and Products 69, 385-394.

Brasil (2009). Regras para análises de sementes do Ministério da Agricultura, Pecuária e Abastecimento. Secretaria de Defesa Agropecuária. MAPA/ ACS.

Cruz, M., Acosta, M., Capote, A., Leiva, M. \& Alvarado, Y. (2003). Efectos del carbendazim para el control de Colletotrichum sp., contaminante del establecimiento in vitro de callos de café. Biotecnologia vegetal, 3(2), 111-113.

De Sá Junior, P. F., Muniz, E. B., Pereira, N. A. \& Oliveira, M. A. S. (2016). Atividade antimicrobiana in vitro dos extratos aquosos, hidroalcoólicos e alcoólicos de espécies da família Anacardiaceae. Revista de Ciências Médicas e Biológicas, 15(1), 56-61.

De Souza Eller, S. C. W., Feitosa, V. A., Arruda, T. A., Antunes, R. M. P. \& Catão, R. M. R. (2015). Avaliação antimicrobiana de extratos vegetais e possível interação farmacológica in vitro. Journal of Basic and Applied Pharmaceutical Sciencies, 36(1), 131-136.

Efferth, T. (2019). Biotechnology Applications of Plant Callus Cultures. Engineering, 5(1), 50-59.

Eichelberger, L. \& Moraes, D. M. (2001). Preparo de sementes de quiabo (Abelmoschusesculentus (L.) Moench) para o teste tetrazólio. Revista Brasileira de Sementes, 23(1), 154-158.

Evans, D. E., Coleman, J. O. D. \& Kearns, A. (2003). Plant Cell Culture, BIOS Scientific Publishers.

Firmo, W. C. A, Menezes, V. J. M, Passos, C. E. C, Dias, C. N, Alves, L. P. L, Dias, I. C. L, Santos Neto, M. \& Olea, R. S. G. (2011). Contexto histórico, uso popular e concepção científica sobre plantas medicinais. Caderno de pesquisa, 18

França, S. C. (2017). Bioprocessos inovadores para produção de metabólitos ativos de plantas. In: Simões, C. M. O., Schenkel, E. P., Mello, J. C. P., Mentz, L. A., Petrovick P. R. (editores). Farmacognosia do produto natural ao medicamento. Artmed, 39-52.

Fumagali, E., Gonçalves, R. A. C., Machado, M. F. P. S., Vidoti, G. J. \& Oliveira, A. J. B. (2008). Produção de metabólitos secundários em cultura de células e tecidos de plantas: o exemplo dos gêneros Tabernaemontana e Aspidosperma. Revista Brasileira de Farmacognosia, 18(4), 627-641.

Gamborg, O. L., Murashige, T., Thorpe, T.A. \& Vasil, I. K. (1976). Plant tissue culture media. In Vitro Cellular \& Developmental Biology - Plant, 12, 473478 .

Gamborg, O., Miller. R. \& Ojima, K. (1968). Nutrient requirements of suspension cultures of soybean root cells. Experimental Cell Research, $50,151-158$.

Grzegorczyk-Karolak, I., Kuźma, L. \& Wysokińska, H. (2015). The effect of cytokinins on shoot proliferation, secondary metabolite production and antioxidant potential in shoot cultures of Scutellaria alpina. Plant Cell, Tissue and Organ Culture (PCTOC), 122, 699-708.

Hartmann, H. T., Kester, D. E., Davies, Jr. \& Geneve, R. L. (2004). Plant propagation: principles and practicas. New York: Prentice Hall, (8a ed.), 880p.

Hayati, S. K., Nurchayati, Y. \& Setiari, N. (2010). Induksi kalus dari hipokotil Alfafa (Medicago sativa) secara in vitro dengan penambahan benzyl amino purine (BAP) dan a-naphtalene acetic acid (NAA). Bioma, 12(1), 6-12.

Hoesen, D. S. H. \& Sukamto, W. La. (2008). Induksi Kalus dan Organogenesis Kultur In Vitro Dendrobium lineale Rolfe. Berita Biologi, 9(3), 333-341.

Hussain, M. S., Fareed, S., Ansari, S., Rahman, M. A., Ahmad, I. Z. \& Saeed, M. (2012). Current approaches toward production of secondary plant metabolites. Journal of Pharmacy and Bioallied Sciences, 4(1), 10-20.

Ikeuchi, M., Sugimoto, K. \& Iwase, A. (2013). Plant callus: mechanisms of induction and repression. The Plant Cell, 25, 3159-3173.

Ishii, Y., Takamura, T., Goi, M. \& Tanaka, M. (2004). Callus induction and somatic embryogenesis of Phalaenopsis. Plant Cell Reports, 17(6), 446-450. 
Jahan, M. T., Islam, M. R., Khan, R., Mamun, A. N. K., Ahmed, G. \& Hakim, L. (2009). In Vitro Clonal Propagation of Anthurium (Anthurium andraeanum L.) using Callus Culture. Plant Tissue Culture and Biotechnology, 19(1), 61-69.

Jamshidi-Kia, F., Lorigooini, Z. \& Amini-Khoei, H. (2018). Medicinal plants: Past history and future perspective. Journal of HerbMed Pharmacology, 7(1), 17.

Kanashiro, S. et al. (2007). Efeitos de diferentes concentrações de nitrogênio no crescimento de Aechmea blanchetiana (Baker) L.B. Sm. cultivada in vitro. Hoehnea, 34(1), 59-66.

Kapepula, P. M., Kabamba, N. N., Tshisekedi, T. P., Tsumbu C., Franck, T., Mouithys-Mickalad, A., Mumba, D., Tshala-Katumbay, D., Serteyn, D., Tits, M., Angenot, L., Kalenda, P. D. T. \& Frédérich, M. (2017). Comparison of metabolic profiles and bioactivities of the leaves of three edible congolese Hibiscus species. Natural Product Research, 31(24), 2885-2892.

Karuppusamy S. A. (2009). review on trends in production of secondary metabolites from higher plants by in vitro tissue, organ and cell cultures. Journal of Medicinal Plant Research, 3(13), 1222-39.

Kinupp, V. F., Lorenzi, H. Plantas Alimentícias Não Convencionais (PANC) no Brasil: guia de identificação, aspectos nutricionais e receitas ilustradas. Nova Odessa, SP: Instituto Plantarum de Estudos da Flora, 768p.

Kutchan, T. M. (2001). Ecological arsenal and developmental dispatcher: the paradigm of secondary metabolism. Plant Physiology, 25(1), 58-60.

Lakshmanan, P. \& Taji, A. (2000). Somatic embryogenesis in leguminous plants. Plant Biology, 2, 136-148.

López-Laredo, A. R., Ramírez-Flores, F. D., Sepúlveda-Jiménez, G. \& Trejo-Tapia, G. (2009). Comparison of metabolite levels in callus of Tecoma stans (L.) Juss. ex Kunth. cultured in photoperiod and darkness. In Vitro Cellular \& Developmental Biology, 45, 4-58.

Lorenzi, H. \& Matos, F. J. A. (2021). Plantas medicinais no Brasil. Jardim Botânico Plantarum. 576p.

Mansuroglu, S. \& Gurel, E. (2001). Micropropagation. In: Babaoglu, M., Gurel, E., Ozcan, S. (editores), Plant Biotechnology, Volume I, Tissue Culture and Its Applications, Selcuk University Press, Konya, Turkey (in Turkish). 262-281.

Manuhara, Y. S. W. (2014). Kapita selekta kultur jaringan tumbuhan. Airlangga University Press.

Mercier, H. \& Kerbauy, G. B. (1998). Endogenous IAA and Cytokinin levels in bromeliad shoots as influenced by glutamine and ammonium nitrate treatments. Revista Brasileira de Fisiologia Vegetal, Brasília, 10(3), 225-228.

Morales-Rubio, M. E.., Espinosa-Leal, C. \& Garza-Padrón, R. A. (2016). Cultivo De Tejidos Vegetales Y Su Aplicación En Productos Naturales. In: RivasMorales C., Oranday-Cardenas, M. A., Verde-Star, M. J (Eds). Investigación en plantas de importancia médica. 1st edn. OmniaScience, Barcelona, p 351-410.

Murashige, T. \& Skoog, F. (1962). A revised medium for rapid growth and bioassays with tobacco tissue cultures. Physiologia Plantarum, $15,473-479$.

Murthy, H. N., Lee, E. J. \& Paek, K. Y. (2014). Production of secondary metabolites from cell and organ cultures: strategies and approaches for biomass improvement and metabolite accumulation. Plant Cell, Tissue and Organ Culture (PCTOC), 118, 1-16.

Nagella, P. \& Murthy, H. N. (2010). Establishment of cell suspension cultures of Withania somnifera for the production of withanolide A. Bioresource Technology, 101(17), 6735-6739.

Nakasha, J. J., Sinniah, U. R., Kemat, N. \& Mallappa, K. S. (2016). Induction, Subculture Cycle, and Regeneration of Callus in Safed Musli (Chlorophytum borivilianum) using Different Types of Phytohormones. Pharmacognosy Magazine, 12(4), 460-464.

Nasution, N. H. \& Nasution, I. W. (2019). The effect of plant growth regulators on callus induction of mangosteen (Garcinia mangostana L.). IOP Conference Series: Earth and Environmental Science, 305.

Naveed, M., Hejazi, V., Abbas, M., Kamboh, A. A., Khan, G. J., Shumzaid, M., Ahmad, F., Babazadeh, D., Fangfang, X., Modarresi-Ghazani, F., Wenhua, L. \& Xiaohui, Z. (2018). Chlorogenic acid (CGA): A pharmacological review and call for further research. Biomedicine \& Pharmacotherapy, $97,67-74$.

Ngomuo, M. S., Mneney, E. \& Ndakidemi, P. (2014). The in vitro propagation techniques for producing banana using shoot tip cultures. American Journal of Plant Sciences, 5, 1614-1622.

Oliveira, N. C. C., Lopes, P. S. N., Ribeiro, L. M., Mercandante-Simões, M. O., Oliveira, L. A. A. \& Silvério, F. O. (2013). Seed structure, germination, and reserve mobilization in Butia capitata (Arecaceae). Trees, 27(6), 1633-1645.

Pawar B., Prashant, K., Bahurupe, J., Jadhav, A., Anil, K. \& Pawar, S. (2015). Proline and Glutamine Improve in vitro Callus Induction and Subsequent Shooting in Rice. Rice Science, 22, 283-289.

Rahman, Z. A., Noor, E. S., Ali, M. S. M., Mirad, R. \& Othman, A. N. (2015). In vitro micropropagation of a valuable medicinal plant Plectranthus amboinicus. American Journal of Plant Sciences, 6, 1091-1097.

Shekhawat, M. \& Manokari, M. (2016). Optimization of in vitro and ex vitro regeneration and micromorphological studies in Basella alba L. Physiology and Molecular Biology of Plants, 22.

Shirin, F., Hossain, M., Kabir, M. F., Roy, M. \& Sarker, S. R. (2007). Callus Induction and Plant Regeneration from Internodal and Leaf Explant of Four Potato (Solanum tuberosum L.) Cultivars. World Journal of Agricultural Sciences, 3(1), 1-6.

Shukla, R., Dube, A. \& Koshy, E. (2014). Production of high quality embryogenic callus of rice. International Journal of Life Science, 9, 1077-1080. 
Research, Society and Development, v. 10, n. 15, e358101523114, 2021

(CC BY 4.0) | ISSN 2525-3409 | DOI: http://dx.doi.org/10.33448/rsd-v10i15.23114

Sitorus, E. N., Hastuti, E. D. \& Setiari, N. (2011). Induksi kalus binahong (Basella rubra L.) secara in vitro pada media Murashige\&Skoog dengan konsentrasi sukrosa yang berbeda. Bioma, 13(1), 1-7.

Sobrinho, A. C. G. \& Santos, A. S. (2020). Estado da arte: Hibiscus sabdariffa Linn, aspectos químicos, farmacológicos e novas perspectivas de abordagens. Revista Científica Multidisciplinar Núcleo do Conhecimento, 5(5), 21-40.

Sobrinho, A. C. G., Santos, A. S. \& Corpes, R. S. (2020a). Aspectos botânicos, morfológicos, germinação e desenvolvimento de plântulas de Hibiscus sabdariffa L. In: Matos, R. R. S. S., Oliveira, A. R. F., Machado, F. G. A. (org.). Floricultura, Plantas Ornamentais e Cultura de Tecidos de Plantas. Ponta Grossa: Atena, 44-55.

Sobrinho, A. C. G., Santos, A. S. \& Corpes, R. S. (2020b). Contaminantes na cultura assimbiótica de Hibiscus sabdariffa L. em diferentes concentrações de meios nutritivos e condições de luminosidade. In: JASPER, M. (org.). Aspectos Fitossanitários da Agricultura. Ponta Grossa: Atena, 2020b. 15-22.

Staba, E. J. (1980). Plant tissue culture as a source of biochemical, CRC Press, Florida.

Tambor, J., Cincotto, M. G. J. A., Leone, B. A. \& Isaac, V. F. M. (2016). Avaliação da atividade antioxidante e fotoprotetora do extrato de cladódios de pitaya (Hylocereus undatus). Journal of Basic and Applied Pharmaceutical Sciencies, 37(1).

Verma, S. K., Das, A. K., Cingoz, G. S., Uslu, E. \& Gurel, E. (2016). Influence of nutrient media on callus induction, somatic embryogenesis and plant regeneration in selected Turkish crocus species. Biotechnol Rep (Amst), 10, 66-74.

Wani, M. \& Snehal, P. N. M. (2010). Callus induction studies in Tridax procumbens L., International Journal of Biotechnology Applications, 2(1), 11-14.

Zouzou, M., Kouadio, Y. J., Koné, M., Kouakou, T. H. \& Dénézon, D. O. (2000). Callogenèse chez Gossypium hirsutum L.: effets cultivar, conditions de culture et type de matériel. Biot Rev Int Sci Vie Terre, 1(1), 48-5. 